\title{
Boletim Informativo sobre contaminados, mortos e imunizados da COVID-19: Amapá, 27 de fevereiro de 2021.
}

Karina Figueira e Jamille Lacerda (1)

\section{EDITORIAL}

Resumo

Artigo informativo trazendo todas as atualizações e dados oficiais mais recentes sobre a pandemia do Covid-19 em todo estado do Amapá. Amapá tem 83.505 casos confirmados, 1.297 em análise laboratorial, 60.476 pessoas recuperadas e 1.139 óbitos. A taxa de imunização é 2,95\% para a primeira dose da vacina.

Palavras Cheave: Covid-19, Amapá, Macapá, Dados oficiais. 


\section{COVID-19 Infectious, Dead and Immunized Information Bulletin: Amapá, February 27, 2021.}

\section{Abstract}

Informative article bringing all the latest updates and official data on the Covid-19 pandemic across the state of Amapá. Amapá has 83,505 confirmed cases, 1,297 in laboratory analysis, 60,476 people recovered and 1,139 deaths. The immunization rate is $2.95 \%$ for the first dose of the vaccine.

Key words: Covid-19, Amapá, Macapá, Official data.

Instituição afiliada: 1- Specialized Dentistry Group.

Dados da publicação: Artigo recebido em 10 de Fevereiro, revisado em 15 de Fevereiro, aceito para publicação em 20 de Fevereiro e publicado em 28 de Fevereiro.

DOI: https://doi.org/10.36557/2674-8169.2021v3n2p05-17

Karina Figueira bjihskarina@gmail.com

cc) (7)

This work is licensed under a Creative Commons Attribution 4.0 International

License. 


\section{BOLETIM}

O Governo do Amapá atualiza neste sábado, 27, o boletim informativo sobre a situação do novo coronavírus no estado. Agora, são 83.505 casos confirmados, 1.297 em análise laboratorial e 27.850 doses de vacinas aplicadas em todo o estado.

Os testes também descartaram 60.136 casos suspeitos.

\section{Novos casos}

O boletim de agora traz 226 novos casos, sendo 120 em Macapá, 38 em Santana, 50 em Laranjal do Jari, 16 em Oiapoque, 1 em Pedra Branca e 1 em Serra do Navio.

\section{Óbitos}

Também há o registro de três novos óbitos no boletim de hoje, sendo dois de Itaubal e um do município de Amapá.

- Um idoso de 86 anos, com insuficiência respiratória aguda, falecido no dia 6 de junho de 2020; o segundo óbito é de um homem de 72 anos, sem informação de comorbidades, falecido no dia 21 de dezembro de 2020. Ambos do município de Itaubal.

- O terceiro óbito é de um homem de 71 anos, natural do município de Amapá, com insuficiência cardíaca, falecido no dia 7 de janeiro de 2021.

Assim, o Amapá chega a com 1.139 óbitos nos 16 municípios. (Macapá: 851/ Santana: 104/ Laranjal do Jari: 57/ Mazagão: 8/ Oiapoque: 28/ Pedra Branca do Amapari: 8/ Porto Grande: 20/ Serra do Navio: 4/ Vitória do Jari: 14/Itaubal: 3/ Tartarugalzinho: 10/ Amapá: 8/ Ferreira Gomes: 6/ Cutias do Araguari: 3/ Calçoene: 9/ Pracuúba: 6).

\section{Recuperados}

Entre os recuperados, estão 60.476 pessoas. (Macapá 25.708/ Santana 7.577/ Laranjal do Jari 5.865/ Mazagão 1.949/ Oiapoque 3.851/ Pedra Branca 3.026/ Porto Grande 1.625/ Serra do Navio 926/ Vitória do Jari 3.214/ Itaubal 360/ Tartarugalzinho 1.598/ Amapá 1.057/ Ferreira Gomes 1.150/ Cutias do Araguari 809/ Calçoene 1.415/ Pracuúba 346).

\section{Vacinação}

Até o momento, o Governo do Amapá distribuiu 46.232 doses de vacinas contra a covid-19 para os municípios. Destas, foram aplicadas 27.850 doses, totalizando, até o momento, $2,95 \%$ da população amapaense que recebeu a primeira dose do imunizante e $0,35 \%$ que recebeu a segunda dose.

\section{Dos 83.505 casos confirmados:}

Macapá: 36.336

Santana: 18.029

Laranjal do Jari: 6.465

Mazagão: 2.299 
Oiapoque: 4.463

Pedra Branca: 3.058

Porto Grande: 1.646

Serra do Navio: 931

Vitória do Jari: 3.250

Itaubal: 362

Tartarugalzinho: 1.719

Amapá: 1.088

Ferreira Gomes: 1.158

Cutias do Araguari: 813

Calçoene: 1.533

Pracuúba: 355

Já em relação aos casos suspeitos, os municípios declaram 1.297, sendo:

Macapá: 1.106

Santana: 106

Laranjal do Jari: 0

Mazagão: 98

Oiapoque: 0

Pedra Branca do Amapari: 0

Porto Grande: 36

Serra do Navio: 6

Vitória do Jari: 0

Itaubal: 0

Tartarugalzinho: 55

Amapá: 2

Ferreira Gomes: 0

Cutias do Araguari: 3

Calçoene: 66

Pracuúba: 0

\section{Isolamento Hospitalar}

O número de pessoas com covid-19 em isolamento hospitalar nas redes pública e privada é de 190 pacientes, sendo 145 casos confirmados e 45 suspeitos.

Entre os casos confirmados, 126 estão no sistema público (57 em leito de UTI /69 em leito clínico) e 19 estão na rede particular (10 em leito de UTI / 9 em leito clínico).

Já entre os casos suspeitos, 21 estão no sistema público (1 em leito de UTI /20 em leito clínico), e 24 estão na rede particular (0 em leito de UTI / 24 em leito clínico).

Com isso, o percentual de ocupação dos leitos voltados para o atendimento da covid-19 no Amapá é de 60,12\%.

Em isolamento familiar: 21.745

Todos estes dados são do Gerenciador de Ambiente Laboratorial (GAL/AP) e do Centro de Informações Estratégicas em Vigilância em Saúde (CIEVS), que auxiliam o Centro de Operações de Emergência em Saúde Pública (COESP) - dispositivo criado pelo Governo do Amapá para gerenciar a crise de COVID-19 no estado ${ }^{1,2}$. 


\section{OS AUTORES DECLARAM NÃO HAVER CONFLITOS DE INTERESSE}

\section{REFERÊNCIAS}

1- Goverdo

do

Estado

Amapá.

Disponivel

em: https://www.amapa.gov.br/noticia/2702/boletim-informativo-covid-19-amapa-27de-fevereiro-de-2021

2- Coelho Paraguassu, É., et al. "The Covid-19 explosion in the state of Amapá: how is the most preserved region in the Brazilian Amazon currently fighting the SARS-COV 2 pandemic?." (2020). 